\title{
A marca Imperator: memória e construção de imagem
}

\section{The Imperator brand: memory and brand building}

\section{ROSA, Vera Zunino}

Escola Superior de Propaganda e Marketing - ESPM-Rio I vzunino@espm.br

\begin{abstract}
Resumo
$\mathrm{O}$ artigo tem como objetivo apresentar brevemente o estudo da marca do Imperator, centro cultural João Nogueira, no que se refere aos aspectos que vão além da sua identidade visual e seu valor, tais como o que a marca representa, a sua imagem, percebida e construída por seus frequentadores, bem como seu valor simbólico, que perpassa por sua história e importância para a região da zona norte da cidade do Rio de Janeiro. A memória afetiva, o resgate do passado ligado à marca e a construção de novos significados pautados no presente do equipamento cultural e nas relações com seus usuários, fazem parte do estudo de reconhecimento e distinção da marca. Assim como, levantar os componentes que conformam o significado da marca a partir de seus aspectos qualitativos e analisar as associações que transpassam o sentido da visualidade e delineiam seu potencial simbólico através da semiótica.
\end{abstract}

Palavras-chave: Memória afetiva. Valores simbólicos. Imagem da marca.

\section{Abstract}

This paper aims to briefly present the study of the Imperator brand - João Nogueira cultural center, in Rio de Janeiro - regarding aspects that go beyond its visual identity and values. Topics of interest include what the brand represents, how the brand image is perceived and built by visitors, and the brand symbolic value, which is so powerful it is embraced by the northern part of the city. The study of brand recognition and distinction covers the affective memory, the brand history, and the construction of new meanings based on the current cultural status of the brand and the relationship with users. In addition to that, this paper aims to identify qualitative aspects that convey the meaning of the brand, and - beyond the visual sense - to analyze the symbolic relationships through Semiotics.

Keywords: Affective memory. Symbolic values. Brand image. 


\section{INTRODUC̣ÃO}

O Imperator, lugar que um dia foi o maior cinema da América Latina, se transformou em casa de shows de grande sucesso, caiu no esquecimento, e por fim ressurgiu como um centro cultural. Está localizado no bairro do Méier, zona norte da cidade do Rio de Janeiro e, desde 2012, se apresenta como um lugar de acolhimento e produção de diferentes linguagens artísticas, agregando a formação de novos espectadores na região e fazendo uma ponte entre público e experiência cultural.

A marca Imperator, através de sua nova identidade, tem se mostrado portadora de significado aos moradores do bairro, e seus eventos trouxeram de modo efetivo um retorno de participação do público local e de outras áreas da cidade, o que se pode confirmar pelos registros do centro cultural em seu site, que contabilizavam, já no primeiro ano de funcionamento, um público de cerca de 700 mil visitantes?'. Teatro, cinemas, exposição permanente e temporárias, shows de música nacional, apresentações de dança e musicais, festival de rock nacional e internacional, além de shows para novas bandas de todos os ritmos, o Imperator vem se consolidando como um ponto privilegiado de cultura da zona norte da cidade.

São poucos os registros históricos e as memórias visuais dessa marca que representa um espaço cultural de tamanha importância para a região e para a cidade. A percepção da marca Imperator junto aos seus usuários, está diretamente relacionada à memória afetiva da antiga representação (do cinema) e da construção de novos significados da sua atual identidade visual. Foram feitas entrevistas, grupos de discussão, questionários para que se pudesse chegar a um diagnóstico e a partir daí análises sobre o material coletado. $\mathrm{O}$ artigo aborda apenas a parte inicial da pesquisa sobre a marca, feita com entrevistas e grupos de discussão.

O poder simbólico da nova identidade visual da marca se coloca como uma proposição para averiguar valores mais específicos como o sentimento de pertencimento das pessoas ao local, que apresenta propostas que vão ao encontro de seus interesses de entretenimento e de cultura.

O Imperator Centro Cultural João Nogueira, quer ser identificado como um polo de cultura que prepara e incentiva o público a vivenciar variadas manifestações temáticas da arte. Isto pode ser observado na sua intensa programação.

1 Os dados foram registrados pela administração do centro cultural e atualizados no seu site, www.imperator.art.br, no mês de junho de 2017, em 4 milhões de visitantes em relação a mais de 2.400 apresentações nas diversas atividades artísticas que apresenta. 
A investigação de seu passado e a análise da imagem da marca em seus desdobramentos, seu significado e valor simbólico, propiciam o estudo de reconhecimento e distinção como signo. Semioticamente é possível levantar os componentes que conformam o significado da marca a partir de seus aspectos qualitativos, mais do que isso, as associações geradas daí podem transpassar o sentido da visualidade da marca e apresentar seu potencial simbólico.

\section{BREVE HISTÓRICO SOBRE O IMPERATOR}

Inaugurado em 21 de maio de 1954, o Cine Imperator foi o primeiro grande cinema da região norte do Rio de Janeiro, sendo considerado o maior da América Latina, com 2.500 lugares. O cine Imperator chamava a atenção por suas dimensões grandiosas e instalações luxuosas, com o uso de materiais nobres no acabamento, bem ao estilo eclético da época.

A galeria do Imperator, que faz a passagem entre o cinema e a rua, tem um traçado bastante original, em curva até o hall e a sala de espera. Citada em jornais da época da inauguração do cinema, como uma das mais importantes, por ter sido transformada em ponto cultural da cidade durante a década de 1950, a galeria ficou inicialmente marcada por exposições como a da Sociedade Brasileira de Belas Artes (DIÁRIO DE NOTÍCIAS, 1956).

Outra forte relação da galeria do cinema com seus frequentadores acontecia com a reunião semanal de jovens para ouvir e dançar ao som do rock ' $n$ ' roll. A "juventude transviada" da zona norte chegava em suas motos e lambretas e, estacionava em frente à galeria. Com roupas e penteados, que se pareciam com as dos filmes americanos, desafiavam os velhos costumes com um linguajar diferente para os padrões da época - as gírias. Um grupo de rapazes ficou conhecido como o "Grupo Imperator". Vestiam calças blue jeans e seu ídolo era James Jean, do filme Rebel without a case, que no Brasil recebeu a tradução de Juventude Transviada. Eram vistos como transgressores da ordem e se diziam injustiçados, acusados de arruaças e brigas, que, afinal, só participavam se fossem provocados. Usavam a galeria do cinema para se divertir e dançar rock pois era um ponto central do bairro e, por muito tempo, aquele foi o lugar em que o estilo musical foi ali celebrado. (ÚLTIMA HORA, 1957).

O cine Imperator e sua galeria se tornaram um espaço de apropriação por jovens e adultos que aproveitavam o local para socializar, mas todos em busca de entretenimento e cultura. A tela panorâmica que atraía as pessoas pela novidade, motivava o público por sua programação de grandes clássicos estrangeiros, como o título americano de sua inauguração, a comédia musical romântica "A meia noite do amor" (Let's do it Again), dirigida por Alexandre Hall (JORNAL DO BRASIL, 1954). 
Com a chegada do primeiro shopping center brasileiro, em 1965, ao Méier (FERNANDES; ANDRADE, 2010), bem próximo ao cinema, numa das principais vias urbanas do bairro, a atenção do público fica dividida, mas suas atrações cinematográficas eram variadas e de boa qualidade. Até o início da década de 1980, manteve a frequência de um bom público aos seus filmes em cartaz, mas o crescimento do bairro, a chegada de novos centros comerciais à região e o grande movimento das vídeo locadoras, provavelmente foram as razões de sua decadência e posterior fechamento em 1986 (ZAREMBA, 2012).

O local ficou fechado por um breve período e foi transformado em casa de grandes shows nacionais e internacionais nos anos 1990. A inauguração em grande estilo aconteceu em setembro de 1991, com o show da atriz Shirley MacLaine. Dirigido inicialmente por três empresários com diferentes competências e empresas próprias na área de shows, resultou na parceria: Klefer, Mills \& Niemeyer. A empresa de Kleber Leite, Klefer Marketing Esportivo e Publicidade, fazia toda a parte de desenvolvimento de marketing, além da publicidade e comunicação dos eventos. Já a empresa Mills \& Niemeyer Promoções Ltda. era responsável pela administração e programação de shows. Luiz Oscar Niemeyer, trazia na bagagem sua experiência na Artplan, empresa de publicidade e promoção de eventos, com a realização do Rock in Rio e, mais tarde, já com sua própria empresa, o Hollywood Rock, o que garantia os contatos com os grandes astros da música e seus empresários e, por consequência, a variada agenda de shows do Imperator. Durante alguns anos a casa brilhou com grandes nomes do cenário musical como Bob Dylan, Tom Jobim, Tina Turner, Lulu Santos, Marisa Monte, entre muitos outros. O local fechou em 1995, porque apesar de todo o sucesso não gerava lucro aos seus empresários. Voltou a abrir em 1996 sob nova direção, com um show de Roberto Carlos. Mas, apesar do estrondoso sucesso de venda de ingressos antecipados, não conseguiu gerar lucro e as novas atrações não superaram os problemas econômicos da casa de shows.

O espaço passou por um período de abandono e quase foi transformado em templo religioso. Sua desapropriação foi determinada em 2002 pelo então governador Anthony Garotinho, que prometia a renovação do espaço com a criação de um centro cultural (CENTRO..., 2013; ZAREMBA, 2012). Mesmo com o declínio de suas atividades artísticas, fracassos de programação e seu fechamento, a marca Imperator ainda era guardiã, na memória de muitos residentes da região, de um tempo de sucesso e prestígio para o bairro.

Em 2010, Luiz Paulo Conde, secretário da cultura do governo de Sérgio Cabral Filho, revendo os projetos dos governos anteriores, consegue viabilizar a transferência do terreno do Imperator do estado para a prefeitura do Rio de Janeiro e, em 2011, começam as obras do Imperator Centro Cultural João Nogueira, culminando com a sua reabertura, em junho de 2012 (CENTRO..., 2013). 
O Imperator não é apenas a revitalização de um espaço público feito pela Secretaria Municipal de Cultura da prefeitura da cidade do Rio de Janeiro, ou mais uma casa para espetáculos, mas um local que apresenta alta qualidade técnica em suas instalações para artistas e público de várias expressões. Foram necessárias modificações no seu projeto arquitetônico, desenvolvido pela Fábrica Arquitetura, sob a responsabilidade do arquiteto João Calafate, para atender às diversas atividades artísticas propostas e possíveis ao novo espaço cultural. O projeto, um desafio entre a renovação e a preservação do espaço arquitetônico, ganhou o 50 prêmio nacional do IAB (Instituto dos Arquitetos do Brasil) como melhor projeto na categoria arquitetura de edificações em 2012 (JAZRA, 2013).

A Secretaria Municipal de Cultura lançou em 2012 um convite, a partir do secretário da época, Emílio Kalil, a grupos privados para gerenciar o centro cultural como uma residência artística - encarregada da programação do equipamento cultural. Vence o projeto seletivo a "Produzir Promoções Artísticas Ltda"., da gestora cultural Aniela Jordan². A residência artística foi uma exceção ao modelo de gestão feito com a empresa privada, responsável por toda a administração, além de se responsabilizar pela parte artística e divulgação da programação, estava também encarregada da manutenção e toda a estrutura do teatro e demais espaços do centro cultural (MESSEDER, 2016).

O nome do centro cultural iria ficar apenas como João Nogueira, seguindo a mesma orientação das Arenas Culturais Cariocas, que foram inauguradas no mesmo ano de 2012, todas na zona norte da cidade e que levam os nomes de ilustres habitantes de seus bairros, mas por insistência da gestora Aniela Jordan, da Associação dos Moradores do Méier e da Associação do Comércio local, foi preservado o nome Imperator por sua força e importância cultural para o bairro da zona norte da cidade. O que se percebeu de imediato, é que havia uma relação de proximidade da população da região com o local, onde a participação em atividades criativas gerava uma troca afetiva, que criava laços de pertencimento. É uma troca material e também uma troca espiritual, é o sentimento de pertencer, que gera identidade. O terraço da edificação foi transformado em praça e é conhecido pelos moradores e frequentadores como Praça Alto Méier.

A comemoração do aniversário do bairro, em 13 de maio, desde 2013, tem sido feita a partir de programação que o centro cultural oferece com a participação da Associação dos Moradores do bairro e a gestão do centro cultural. Os shows são oferecidos a preços populares e a festa na Praça Alto Méier é aberta a todos. A realização destas e outras ações com a comunidade local fazem com que o Imperator retome seu lugar na memória do bairro e a marca se fortaleça.

2 Aniela Jordan, tem importante ligação com a produção cultural por suas experiências na área de shows e teatros musicais na empresa Aventura, da qual é sócia. 


\section{MARCA E A CONSTRUC̣ÃO DE UMA NOVA IMAGEM}

Marca é um código especial de leitura que dá significado ao que representa. "A marca é nome, um termo, um sinal, ou um desenho, ou uma combinação destes elementos, com vista a identificar os produtos e serviços de um vendedor ou de um grupo de vendedores, e a diferenciá-los dos concorrentes", como define a Associação Americana de Marketing. A semiótica como o estudo dos signos pode oferecer vasto instrumental para o estudo da marca junto ao marketing analisando textos e imagens publicitárias, segundo Perez (2016), que define a marca como "uma conexão simbólica e afetiva estabelecida entre uma organização, sua oferta material, intangível e aspiracional e as pessoas para as quais se destina" (PEREZ, 2016, p. 10).

A marca é bem mais do que uma representação gráfica, ela representa a imagem de um produto, a sua personalidade exclusiva que se expande para seus atributos e benefícios, sejam eles tangíveis ou intangíveis. Hoje a imagem da marca está associada às percepções e associações ligadas a um produto, empresa ou indivíduo (BATEY, 2010) A marca é um signo duplo, ambivalente, um signo sensível, ao mesmo tempo verbal e visual. Verbal por ter um nome e visual, segundo Costa (2011), porque precisa se estabilizar, se fixar no espaço visível porque a palavra, o nome no meio sonoro é volátil e imaterial.

Branding poderia ser traduzido, literalmente, como sendo a ação de marcar. O termo é relativamente recente e está ligado ao potencial de gerenciamento das marcas. A gestão de marcas está relacionada à identidade de uma marca e como ela é percebida, seja ela um start up, uma empresa de grande porte ou uma instituição sem fins lucrativos (WHEELER, 2012).

Neumeier (2008) diz que o sucesso de uma marca para ser duradouro depende de uma "constante regeneração" de sua memória corporativa, apontando uma renovação através de "um programa educacional" que garanta sua sobrevivência criativa e seu estado de alerta em ouvir o seu consumidor. No caso do Imperator, a sua gestão não depende só de um programa de renovação apresentado a cada ano pela empresa privada que o administra, "Produzir", mas também da estabilidade política da Prefeitura que, com a mudança em seu quadro de dirigentes se coloca como uma incógnita ao futuro do centro cultural.

O Imperator em seu breve tempo de vida como centro cultural, com apenas cinco anos, tem demonstrado sua vontade em cativar e transmitir confiança, voltado para as ações culturais junto à comunidade. Com isso mantém cursos direcionados para diversos públicos, como o de percussão, em que jovens iniciam seu aprendizado musical direcionado às escolas de samba ou grupos de samba que proliferam na região, do mesmo modo que o curso de mestre sala e porta bandeira para crianças e jovens, reforça a vocação de promover novos sambistas. 
Além do samba, o Méier concentra algumas boas escolas de dança, de balé clássico e moderno. O Imperator também dispõe de aulas de balé gratuito para diferentes faixas etárias, além de promover workshops com profissionais de importantes instituições nacionais e internacionais como o Bolshoi Brasil e Miami City Ballet School. O coral Imperator é outra ação que cativa a relação com a comunidade, propicia o entrosamento entre pessoas de idades diferentes e anualmente apresenta o resultado de seus ensaios musicais em que a movimentação corporal, com base no gestual do teatro musical, faz a diferença.

A representação gráfica da marca Imperator como centro cultural foi criada em 2012 pelo designer Luciano Mello. A assinatura completa da marca apresenta o complemento: Centro Cultural João Nogueira. Os frequentadores, apesar de reconhecerem, raramente utilizam o nome que faz homenagem ao compositor que viveu no Méier durante quase toda a sua vida. A instituição é conhecida apenas como Imperator. Um nome forte, sonoro, que está relacionado e impregnado na memória de muitos frequentadores dos diferentes tempos de atuação do local.

Figura 1 - Assinatura vertical da marca Imperator.

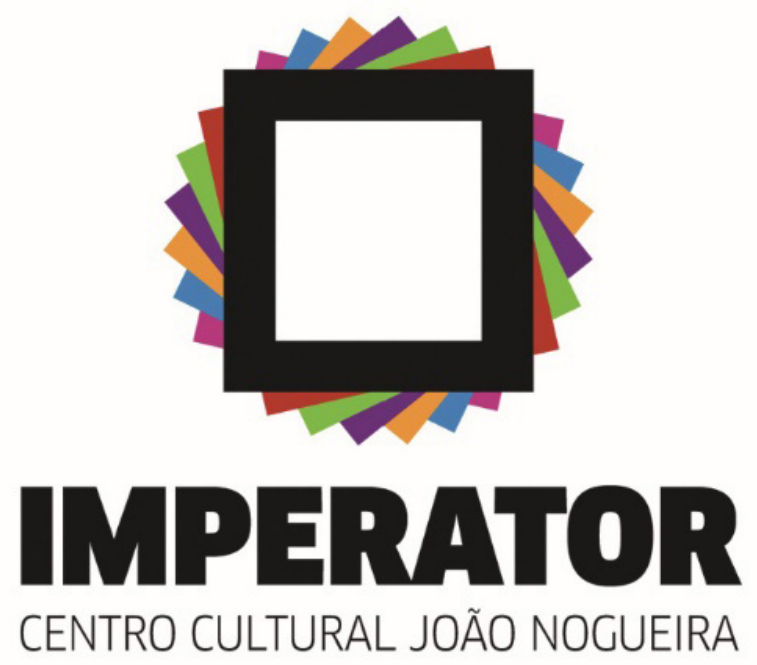

Fonte: (CENTRO..., 2013).

A mudança na identidade visual de uma marca geralmente causa reação e quase sempre de modo não positivo. Tanto Wheeler (2012), quanto Aaker (1998), defendem que criar uma nova marca é mais fácil do que a mudança do nome de uma organização já existente, pois significa gerar expectativas sobre a empresa e imagem anterior, já fixada na mente de consumidores. Exige, além de tudo, um esforço de organização em apresentar com clareza as principais mensagens em torno das mudanças. Os maiores desafios são listados como os prazos e orçamentos adequados, planejamento do lançamento, manter um foco estratégico em todas as comunicações, honrar a herança do passado e celebrar o que é novo e alcançar todos os públicos. 
Os desafios no caso do Imperator foram bastante representativos, pois a participação da empresa gestora "Produzir" só se efetivou muito próximo à data de abertura do centro cultural, divulgada pela Prefeitura para o primeiro semestre de 2012. O planejamento para as etapas de criação da marca e lançamento de uma campanha apresentando o novo espaço, sob a orientação dos sócios da "Produzir", não foi suficiente, assim como a verba destinada para este fim.

Mark Batey (2010), consultor em marcas, fala da criação de um sistema de identidade visual integrado e pertinente ao objeto e de como os consumidores estabelecem relações entre o significado e o valor simbólico de uma marca, complementando bem os conceitos de branding. Para o autor, o significado é construído através dos elementos gerados pela propaganda que fazem parte da estratégia de marketing, para o reconhecimento de uma marca e, principalmente, pela experiência do consumidor. Quando surgem no mercado, as marcas não apresentam significado, esses são construídos a partir da experiência, do uso do produto ou serviço, da indicação de um amigo e com o tempo, as características simbólicas começam a se formar. Batey coloca que o significado foi surgindo com o desenvolvimento das marcas, pois até o início do século $X X$ muitos produtos eram vendidos sem marcas e embalagens, e que este seria o primeiro estágio pelo qual passa um produto, em que ele é um commodity ${ }^{3}$. O segundo estágio mostra a marca como referência, onde já existe uma distinção entre os produtos por seus benefícios funcionais, em que o nome do produto começa a ter importância por ser uma garantia de qualidade. No terceiro estágio, é difícil distinguir uma diferença competitiva nos produtos ou serviços, portanto, as marcas começam a apresentar uma personalidade, um apelo emocional que traz proximidade ao consumidor, que começa a moldar um significado para elas. O último estágio mostra que algumas marcas se tornam ícones, carregados de significado para grupos de pessoas. "Na hora em que se chega a este ponto, em que a marca começa a representar algo maior do que ela e seu significado é principalmente simbólico, ela efetivamente se deslocou do ciclo de vida do produto, como tradicionalmente se define." (BATEY, 2010, p. 312)

O Imperator como centro cultural ultrapassou as primeiras etapas e, desde sua inauguração, um apelo emocional, trazendo de volta antigos frequentadores e aproximando um público novo, começando a trabalhar um significado simbólico junto a eles. Passados cinco anos de sua abertura, começa a ser percebido pelas pesquisas, que $\mathrm{o}$ aparelho cultural ganhou significado para a zona norte da cidade do Rio de Janeiro e, mesmo em meio a crise econômica, tem apresentado um volume de atrações e de público bastante relevantes.

3 Commodity é um termo usado para definir as mercadorias, matérias primas básicas como os produtos agrícolas - arroz, açúcar ou minério de ferro. 
A imagem da marca, determina as múltiplas dimensões reais e simbólicas, que permanecem na lembrança das pessoas, como aponta Costa (2011), mesmo quando o objeto já não existe mais, caso da marca Imperator, da sua força expressiva mesmo após tantos anos do cinema e da casa de shows terem sido fechados. A marca ainda existia na memória das pessoas.

O universo simbólico da marca é muito maior do que um produto ou serviço, é a sua capacidade de comunicação que elabora um sentido, que se instaura na relação entre a marca e seus consumidores e clientes. Está, portanto, ligada às experiências com marcas principalmente ligadas a serviços, como no caso do Imperator, que desde seu aparecimento como cinema gerava um valor agregado ligado ao lazer e à socialização do espaço. A galeria de acesso ao cinema era um local de encontros e se firmou na memória de seus usuários. A dimensão da experiência emocional, no caso Imperator, se faz novamente presente quando retorna como uma casa de espetáculos e, se torna um ambiente de novas atrações memoráveis que foram vividas por seus usuários.

\begin{abstract}
A relação emocional ótima, a experiência vivida como uma impressão intensa, só é produzida no lugar da marca. Quando a marca joga em sua casa, ela é a rainha. Todas as condições para o triunfo pleno estão potencialmente aí. O espaço delimitado é o território direto da marca. A personalidade do ambiente e seu poder indutivo são fatores especialmente estimulantes, energizantes, que interagem com a consciência de desejo dos indivíduos. (COSTA, 2011, p. 115).
\end{abstract}

O autor dá destaque ao lugar da marca, o seu ambiente, e diz que não pode ser qualquer lugar, mas sim um lugar envolvente para que as emoções possam fluir. E se o ambiente faz parte da magia da marca, o atual Imperator é o lugar certo para envolver seus usuários em torno das suas atrações. A criação de programas especialmente voltados para um público mais maduro, faz parte desse envolvimento. Há um cuidado especial na criação de um horário mais cedo, às 16 horas, e um local para encontro entre o público e artistas após as apresentações.

\title{
4 MARCA E MEMÓRIA AFETIVA
}

Pierre Nora (1993), traduz memória como vida e que não tem o mesmo sentido de história, pois a memória permanece em evolução e, como tal, estaria vulnerável às distorções involuntárias, seja pelo esquecimento ou pela lembrança das pessoas. Enquanto a história seria a representação do passado, de algo que não existe mais, a memória seria como um elo do passado vivido no presente. Para o autor, a história é uma operação intelectual, que interpreta 
e analisa o que transcreve, enquanto a memória é afetiva, pois se alimenta das lembranças particulares e ligada a subjetividade de quem a projeta. $\mathrm{O}$ autor diz que a memória instala a lembrança no sagrado, enquanto a história a liberta ou se distancia pelo seu discurso laico e crítico. Com isso quer demonstrar as diferenças entre o caráter subjetivo da memória e a estrutura organizada da história. A condução de seu pensamento fica melhor entendida quando afirma que a memória é "múltipla, coletiva, plural e individualizada" (NORA, 1993, p. 9), já que emerge de um grupo que se une em torno dela, enquanto posiciona a história como de todos e ao mesmo tempo de ninguém e, por isso universal.

Foi o mesmo autor, Nora (1993), quem cunhou o conceito de lugar de memória que relaciona ao mesmo tempo o que é material, simbólico e funcional, mesmo que em diferentes graus.

Os lugares da memória seriam organizações que perderam sua espontaneidade, traduzidos "sob o olhar de uma história reconstituída" e, "antes de tudo, restos" (NORA, 1993, p. 12). A valorização do que é novo faz com que os arquivos, museus, coleções, comemorações, monumentos e outros recursos tidos como lugares de memória, sejam apenas marcos testemunhais de outras épocas. Para o autor não existe mais memória, tudo teria se transformado em história, pois a memória deixa de ser espontânea para ser um dever e que o armazenamento, ou seja, a produção de arquivos de memória hoje é incentivada por empresas públicas e privadas, o que fez com que a materialização da memória tenha se dilatado, pois tudo pode ser registrado, mas alerta que por mais que se arquive tanta informação, sempre ficará alguma coisa de fora.

O autor explica que mesmo um arquivo só é lugar de memória se estiver revestido de simbolismo e diz que os lugares são referências. "Os lugares de memória vivem de sua aptidão para a metamorfose, para ressaltar seus significados" (NORA, 1993, p. 27).

A construção do Imperator, como referência de lugar cultural, se inscreve na sua história e na memória de seus frequentadores. O lugar de memória é determinado pelo espaço físico no qual se fizeram presentes o cinema, na década de 1950, a casa de shows, na década de 1990, e atualmente o centro cultural, desde 2012. O seu próprio nome carrega a mágica do cinema, simbólico por sua significação de tempos românticos e da juventude transviada; traduz o encantamento de uma casa noturna, que respirava música e atraía multidões e, que se transformou novamente num lugar de encontros, de socialização e realização cultural.

Sobre a memória afetiva, Russo e Herkket (2008) relacionam objetos que atuam como uma referência de memórias, são objetos que servem como autenticadores de lembranças. Os autores dizem que a emoção é um sintoma e funciona como uma ferramenta de sobrevivência, onde os sentidos atuam como sensores. 
No caso do Imperator, a memória afetiva se refere ao local em geral ou um específico citado nas entrevistas com frequentadores da época do cinema: a galeria, um lugar que ficou marcado pelas relações e associações feitas à ela. As pessoas contam histórias sobre os encontros na galeria e como o local era usado para dançar rock and roll. A loja de doces e balas que ficava em frente ao cinema, já ao final da galeria, também foi citada com as marcas de bala da época: balas Boneco e as de caramelo com chocolate, Toffe, ambas da marca Bhering.

Já os frequentadores do Imperator casa de shows, guardavam como lembrança alguns cardápios produzidos especialmente para o bistrô que havia na época (anos 1990).

Os frequentadores do centro cultural sentem prazer em estar nos diversos ambientes do local e tomam os espaços como seus, preservando e cuidando, principalmente das salas dos projetos abertos à comunidade como os de música e dança clássica no segundo piso e a sala usada para as de mestresala e porta-bandeira, no terraço.

\section{MARCA E SEMIÓTICA}

Empiricamente se diz que a primeira impressão é a que fica e nem sempre isso resulta em uma verdade, mas, no caso das imagens e das marcas, a primeira impressão provoca reações resultantes das características qualitativas que as formas, cores, texturas, volumes e outros aspectos percebidos visualmente nos causam de imediato. Nöth e Santaella (2010) esclarecem que impressões são sempre vagas e dificilmente podem ser analisadas isoladamente, pois são percebidas ao mesmo tempo. Acrescentam que as qualidades e seus efeitos sensoriais não se reduzem às primeiras impressões e que somos afetados por efeitos advindos das cores e formas. Assim, colocam que as qualidades nos levam a associações por semelhança, tanto nas cores, quanto nas formas, e que os efeitos sugestivos a partir das qualidades se estendem também a comparações abstratas como delicadeza, harmonia e outras qualidades não visíveis nas cores e formas. Com isso os autores apresentam as possibilidades de leituras de marcas partindo das referências dos signos com os objetos que os ícones apresentam, do que indicam através dos índices e do que representam nos símbolos (NÖTH; SANTAELLA, 2010).

Nos estudos semióticos de uma marca, o objetivo é captar e comunicar um conjunto de atributos que possam expressar as qualidades desejadas para que sejam percebidas e validadas por seus clientes.

A marca Imperator, em sua forma, remete à simplicidade do espaço arquitetônico, através de um elemento geométrico: o quadrado, que por sua vez 
representa simbolicamente o centro cultural. Os demais elementos quadrados coloridos também sugerem a diversidade de expressões da arte encontradas nele. As cores fazem uma relação com as atividades, indicam e representam parte do objeto dinâmico.

Fernandes (2008), diz que a experiência sinestésica é muito importante no exercício de atribuir significados e dar sentido às coisas através da cor. Com isso, pode-se justificar a atribuição de sentido dado pelo designer da marca, Luciano Mello, aos quadrados coloridos: ao vermelho atribuiu a força da expressão teatral; ao verde a juventude ou a harmonia da música; ao roxo o mistério e emoção do cinema; o estímulo, vivacidade e criatividade atribuiu à cor laranja associada às exposições; ao quadrado azul, concentração, afeto, representando a convivência; e à cor lilás a alquimia e a magia da gastronomia.

Figura 2 - Marca Imperator: Símbolo e componentes relacionais com suas cores.

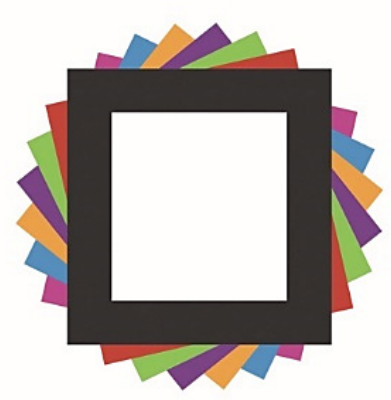

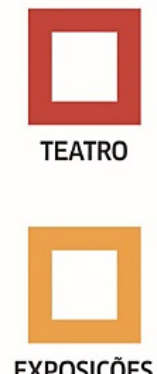

EXPOSIÇÕES

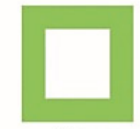

MÚSICA

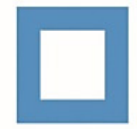

CONVIVÊNCIA

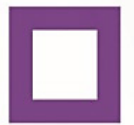

CINEMA

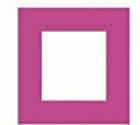

GASTRONOMIA

Fonte: (CENTRO...,2013).

A percepção que temos das marcas pode variar entre atração, indiferença ou repulsa que resulta da forma, volume, cor, textura, distribuição dos elementos que o design apresenta (NÖTH; SANTAELLA, 2010). A marca do Imperator aparenta luminosidade no quadrado central branco, realçado pelas cores rebatidas nas laterais e pelo contraste do fio preto que delimita a forma. $O$ quadrado representa rigidez, organização, ligado à racionalidade e à ordem. As linhas retas da tipografia transmitem a mesma impressão de solidez do quadrado, resultando numa leitura equilibrada, de boa organização e percepção, segundo a interpretação da autora desse artigo.

As qualidades expressivas e representacionais são aspectos da dimensão semântica de um produto que agrega aspectos de referência às dimensões anteriores. Embora Niemeyer (2007), faça referência ao aspecto semântico como tratando das possibilidades de descrição de um objeto dinâmico, o que se pode transpor para a marca Imperator é a forma como sua identidade pode ser representada e reconhecida. As assinaturas da marca nem sempre têm uma boa percepção em algum dos fundos aplicados, mas o peso do nome Imperator em caixa alta, faz um destaque e permite caracterizar a percepção do nome como objeto principal. 
As referências icônicas, indiciais e simbólicas são indicações de como elementos presentes num objeto dinâmico podem propor interpretações, segundo Niemeyer (2007), desse modo podemos relacionar a marca com cada uma das categorias para uma análise semiótica.

Na categoria icônica, o aspecto de semelhança da forma é a base para imagens, estruturas, organizações ou metáforas observadas num objeto e a marca Imperator tem um elemento de sua forma, o quadrado, que guarda semelhança com a arquitetura do prédio do centro cultural. Não há, entretanto, semelhança cromática e sim uma associação de cores em relação aos vários ambientes do local. Na categoria ou referência indicial, está presente de modo sutil uma determinação de causalidade. A forma percebida pelas pontas dos quadrados coloridos sugerem movimento. As referências simbólicas são estabelecidas e difundidas culturalmente, e, desse modo, passam a ser reconhecidas; no caso das marcas a difusão é feita através de meios de comunicação diversos. A marca é um conjunto de elementos gráficos tais como os nomes e formas, que correspondem a signos representativos de produtos, serviços ou instituições. A marca Imperator tem grafados os nomes em tipografia bastonada, o que remete a sua forma simbólica pelos traços retos. As cores também são elementos simbólicos que impregnam de sentido o conjunto da marca pela variedade usada e o modo como foram relacionadas aos ambientes do local.

Desde a sua inauguração, em 2012, a fachada apresenta uma semelhança com o painel de letreiros do cinema, com o logotipo no topo, e, no centro de um moderno painel digital, que ainda está em funcionamento e onde projetam os destaques da programação do centro cultural. Na lateral esquerda ficava a aplicação do brasão da cidade, ao lado da logotipia da Prefeitura do Rio de Janeiro. E, na lateral direita, as indicações de cada serviço oferecido. No início de 2017, a organização da fachada mudou, embora o logotipo tenha permanecido centralizado e no mesmo lugar do nome Imperator, desde os tempos do cinema. Na lateral direita foi aplicado o símbolo em sua versão branco sobre fundo preto, com perda de leitura e expressão por causa dos traços finos que complementam o quadrado central.

Figura 3 - Fachada com alteração de 2017 e aplicação de símbolo com perda de leitura.

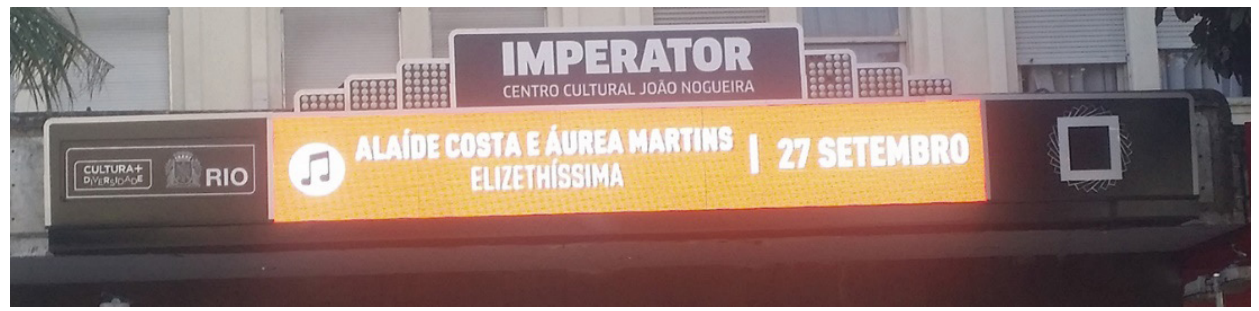

Fonte: Da autora. 
Comparando as fachadas, percebemos que na atual, ao grafar o nome Imperator, com peso e destaque maior do que o nome Centro Cultural João Nogueira na linha inferior da logotipia, foi dado um destaque ao nome, reforçando sua distinção e dando reconhecimento como protagonista de um passado cultural. A tipografia bastonada da logotipia atual traz, na sua forma, uma semelhança visual com a do antigo cinema.

Figura 4 - Fachada do cinema Imperator, da década de 1980.

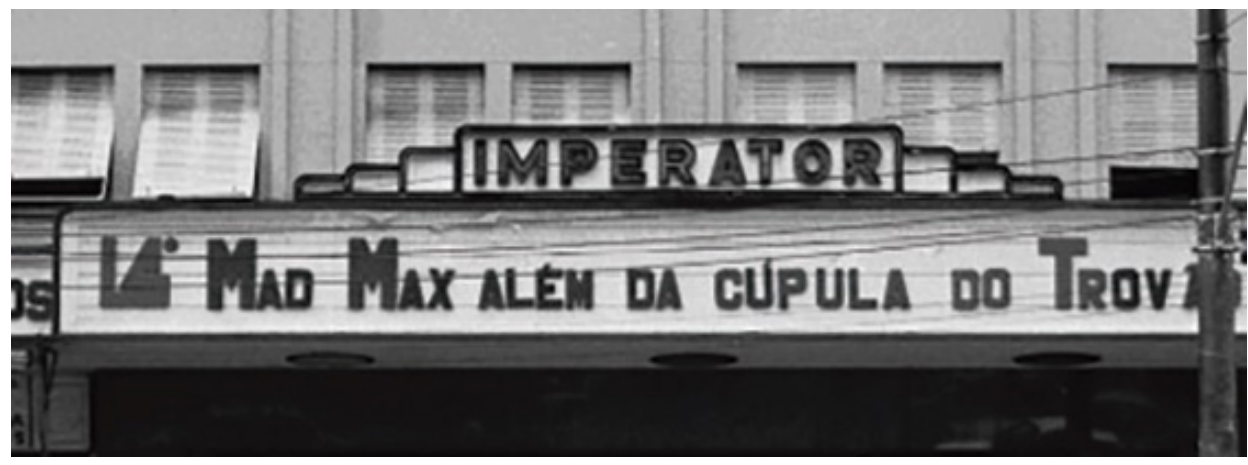

Fonte: O Globo, arquivo digital.

\subsection{A Marca e a Percepção de Seus Frequentadores}

Uma pesquisa pode ser definida como um procedimento de ordem sistemática que tem por fim chegar a respostas de um determinado problema proposto a ser investigado, segundo Gil (2002). Diante das suas variáveis e do objeto aqui estudado, as pesquisas qualitativas se colocam como ferramentas com o propósito de apresentar caminhos a serem investigados com possibilidade de maior profundidade. Dentre as técnicas de pesquisa qualitativas foram consideradas para o estudo do tema alguns métodos como: minigrupo focal e entrevistas semiestruturadas.

Grupo focal é uma técnica de investigação qualitativa que analisa o resultado da interação de grupos reunidos para discutir um tópico colocado pelo pesquisador, segundo Gondim (2003). A autora complementa a conceituação dizendo que o processo é utilizado para reconhecer as percepções de um grupo e se "coloca numa posição intermediária entre a observação participante e as entrevistas em profundidade" (GONDIM, 2003, p. 151). No caso dos grupos pesquisados no Imperator, foram usados dois grupos com quatro participantes para que se pudesse ter uma visão entre o público bem jovem (entre 17 e 20 anos) e um público bem maduro (entre 50 e 70 anos) sobre a marca, sua imagem e relações simbólicas.

As diferenças de idade marcam quanto à relação simbólica demonstrada pelas participantes mais idosas. Elas vivenciaram momentos no local e se referem com emoção ao passado. Os mais novos estão construindo relações a 
partir de outras referências: pelas redes sociais ou por um filme (documentário sobre o grupo de rock Legião Urbana), que foi citado durante os depoimentos.

A emoção relacionada à marca pelo grupo de senhoras é traduzida pela palavra saudade e a dos jovens alegria. Já quanto a palavra que dá sentido à marca, diversidade foi citada nos dois grupos. Quanto à forma os dois grupos observam que na marca o que tem mais força é a palavra, o nome "Imperator". A imagem do centro cultural está em construção como um lugar de acolhimento e diversidade, para ambos os grupos.

\section{CONCLUSÕES}

Marcado pelo passado que remete ao maior cinema da América Latina e casa de espetáculos, o atual equipamento cultural, restituiu o orgulho dos moradores do bairro do Méier.

A dimensão da recepção da representação de um símbolo foi o objeto principal desse estudo alicerçado por técnicas de pesquisas, voltadas para o ser humano que interpreta continuamente o mundo em que vive. Ligada às teorias de comunicação, a semiótica trata da produção do sentido e está direcionada para a potencialidade da emissão de uma marca.

As pesquisas feitas em grupos de discussão não conseguiram abordar em profundidade o valor afetivo da marca, mas traduziram o conhecimento e o carinho com que o público mais velho relatava suas breves memórias sobre o local. Os mais jovens, da mesma forma, demonstraram apreciar o local e suas possibilidades, embora conheçam pouco sobre o passado do centro cultural. Percebem a marca em seu conjunto, mas, assim como para os mais velhos é o nome Imperator que associam ao local.

Alguns pontos fracos, a marca deixa transparecer, como a falta de percepção do público mais velho, frequentador do centro cultural, para o conjunto de elementos visuais da marca. Os mais jovens reconhecem a nova forma que caracteriza a marca, mas a maioria também reconhece que o nome Imperator é a representação mais significativa do centro cultural. Pode-se, portanto, considerar o ponto forte a manutenção do nome Imperator.

Um ponto positivo, para agregar valor afetivo e simbólico à marca, foi a manutenção da fachada com as mesmas características formais do cinema. Em toda a história do Imperator, a fachada escalonada foi mantida.

Os benefícios intangíveis da marca, relacionados aos benefícios emocionais que se delinearam na pesquisa de discussão de grupos, apontam para a alegria e sentimento de pertencimento, declarado principalmente 
pelo público mais velho. Os benefícios tangíveis e funcionais da marca, que se colocaram mais visíveis na pesquisa, apontam como um local de variadas opções de lazer e cultura, com eventos para vários públicos.

Geralmente, os nomes dos centros culturais são longos e nem sempre fáceis de memorizar, mas o nome Imperator estabelece uma conexão com os moradores do Méier e bairros próximos, principalmente aqueles que já conheciam as atuações culturais anteriores do espaço. O nome certo para uma marca é atemporal, fácil de lembrar, como afirma Wheeler (2012). O nome Imperator é significativo e carrega a essência da marca, como apontaram as pesquisas e a fala de um de seus gestores: "um carioca ilustre" que voltou, que retomou seu lugar trazendo uma série de opções culturais, que geram conhecimento.

O branding tem importante papel para gerar valor às marcas e para isso as organizações têm investido num posicionamento mais arrojado, em que as pessoas são ouvidas sobre seus sentimentos em relação a elas. E, nesse sentido, a gestão da marca Imperator tem procurado se aproximar de seu público, ouvir suas demandas, seja para ajustar a programação, ou ampliar sua atuação na esfera educativa. O envolvimento com ações sociais é também um meio de fazer com que haja uma participação do frequentador do centro cultural com as necessidades da comunidade de seu entorno e fortalecer a imagem da marca. A marca Imperator representa, nos relatos e entrevistas, um lugar de encontro, um lugar onde há diversidade de atrações, onde as pessoas gostam de estar, se sentem bem e fazem amizades. 


\section{REFERÊNCIAS}

AAKER, David. Marcas: brand equity, gerenciando o valor da marca. São Paulo: Negócio, 1998.

BATEY, Mark. O significado da marca: como as marcas ganham vida na mente dos consumidores. Rio de Janeiro: Best Business, 2010.

CENTRO Cultural João Nogueira. Projetos, São Paulo, v. 145, n. 2, 13 jan. 2013. Disponível em: <http://www.vitruvius.com.br/revistas/read/ projetos/13.145/4641>. Acesso em: 20 abr. 2016.

COSTA, Joan. A imagem da marca. São Paulo: Rosari, 2011.

DIÁRIO DE NOTÍCIAS, Rio de Janeiro, Suplemento Literário, p. 5, 22 jan. 1956. Arquivo Biblioteca Nacional. Disponível em: <http://memoria.bn.br/>. Acesso em: 11 abr. 2016.

FERNANDES, Nelson da Nóbrega; ANDRADE, Charles Albert. Origens dos shoppings centers no Brasil: a primeira onda de shoppings nos anos $1960 \mathrm{e}$ 1970. In: ENCONTRO NACIONAL DOS GEÓGRAFOS, 16., 2010, Porto Alegre. Anais... Porto Alegre, 2010. p. 5.

GIL, Antonio Carlos. Como elaborar projetos de pesquisa. São Paulo: Atlas, 2002.

GONDIM, Sônia Maria Guedes. Grupos focais como técnica de investigação qualitativa: desafios metodológicos, Paidéia, Ribeirão Preto, v. 12, n. 24, p. 149161, 2003. Disponível em: <http://www.scielo.br/pdf/paideia/v12n24/04.pdf>. Acesso em: 2 nov. 2016.

JAZRA, Gustavo. IAB-RJ divulga vencedores de sua 50ạ Premiação Anual. PINI WEB, 11 jan. 2013. Disponível em: <http://piniweb.pini.com.br/construcao/ arquitetura/premiacao-iab-rj-276308-1.aspx>. Acesso em: 20 abr. 2016.

JORNAL DO BRASIL. Rio de Janeiro, p. 9, 21 maio 1954. Arquivo Biblioteca Nacional. Disponível em: <http://memoria.bn.br/DocReader/docreader. aspx?bib=030015_07\&pasta=ano\%20195\&pesq=cine\%20Imperator $>$. Acesso em: 11 abr. 2016.

MESSEDER, Carlos Alberto. Um olhar sobre a política cultural carioca e o audiovisual. Rio de Janeiro: E-papers, 2016. v. 1.

NEUMEIER, Marty. The brand gap: o abismo da marca. Como construir a ponte entre a estratégia e o design. Porto Alegre: Bookman, 2008.

NIEMEYER, Lucy. Elementos da semiótica aplicados ao design. Rio de Janeiro: Ed. 2AB, 2007.

NORA, Pierre. Entre memória e história: a problemática dos lugares. Projeto História: Revista do Programa de Estudos Pós-Graduados de História, São Paulo, v. 10, 1993. Disponível em: <https://revistas.pucsp.br/index.php/revph/ article/viewFile/12101/8763>. Acesso em: 3 abr. 2017. 
NÖTH, Winfried; SANTAELLA, Lucia. Estratégias semióticas da publicidade. São Paulo: Cengage Learning, 2010.

PEREZ, Clotilde. Signos da marca: expressividade e sensioralidade. São Paulo: Cengage Learning, 2016.

RUSSO, Beatriz; HEKKERT, Paul. Sobre amar um produto: os princípios fundamentais. In: MONTALVÃO, Cláudia; DAMAZIO, Vera (Org.). Design ergonomia emoção. Rio de Janeiro: Mauad, 2008.

ÚLTIMA HORA. Rio de Janeiro, p. 8, 13, maio 1957. Arquivo Biblioteca Nacional. Disponível em: <http://memoria.bn.br/>. Acesso em: 11 abr. 2016.

WHEELER, Alina. Design de identidade da marca: guia essencial para toda a equipe de gestão de marcas. Porto Alegre: Bookman, 2012.

ZAREMBA, Isabela. Imperator: a história do lugar que marcou e ainda marcará muitas gerações. 2012. Disponível em: <https://agendaculturalrj.wordpress. com/2012/11/08/imperator-a-historia-do-lugar-que-marcou-e-aindamarcara-muitas-geracoes/>. Acesso em: 18 abr. 2016. 